Article

\title{
Analysis of Cavity PD Characteristics' Sensitivity to Changes in the Supply Voltage Frequency
}

\author{
Tapiwa Venge * (1) and Cuthbert Nyamupangedengu *
}

School of Electrical and Information Engineering (EIE), Faculty of Engineering and the Built Environment (EBE), University of the Witwatersrand Johannesburg, Private Bag 3, Johannesburg 2050, South Africa

* Correspondence: tapiwa.venge@students.wits.ac.za (T.V.); cuthbert.nyamupangedengu@wits.ac.za (C.N.)

\begin{abstract}
The supply voltage frequency effect on partial discharge (PD) phenomena has continued to draw research interest. Although most high voltage equipment operates at power frequency $(50 / 60 \mathrm{~Hz})$, testing is often done at different frequencies for various reasons. Despite some agreements and inconsistencies for the research findings of PD activity's frequency dependence, there has been consensus on the recognition of the discharge mechanism parameters that influence how the supply voltage frequency affects PD activity. These parameters include statistical time lag, discharge area surface conductivity, and the residual charge decay. In this paper, a 3-capacitor model (ABC) is used to simulate how the changes in the discharge mechanism parameters influence PD characteristics as a function of the supply voltage frequency. The findings are that the phase-resolved partial discharge pattern (PRPDP) and PD repetition rate (PDRR) characteristics are more sensitive to variations in the probability of the seed electron availability at higher frequencies of the supply voltage. The opposite trend is observed for the cavity surface resistance. At lower resistance of cavity surface, the PRPDP and PDRR characteristics are more sensitive to changes in the supply voltage frequency than at higher resistances. The paper also confirms that incorporating equivalent resistances in the $\mathrm{ABC}$ model makes it more authentic than the model comprising of capacitors only.
\end{abstract}

Keywords: 3-capacitor model; ABC model; frequent dependent mechanisms; partial discharges; statistical time lag; supply voltage frequency; surface conductivity

Citation: Venge, T.;

Nyamupangedengu, C. Analysis of Cavity PD Characteristics' Sensitivity to Changes in the Supply Voltage Frequency. Energies 2021, 14, 478. https://doi.org/10.3390/en14020478

Received: 3 December 2020 Accepted: 13 January 2021 Published: 18 January 2021

Publisher's Note: MDPI stays neutral with regard to jurisdictional clai$\mathrm{ms}$ in published maps and institutional affiliations.

Copyright: (C) 2021 by the authors. Licensee MDPI, Basel, Switzerland. This article is an open access article distributed under the terms and conditions of the Creative Commons Attribution (CC BY) license (https:// creativecommons.org/licenses/by/ $4.0 /)$.

\section{Introduction}

Insulation is often regarded as the weakest part of high voltage and medium voltage equipment [1]. As an example, according to the IEEE Recommended Practice for the Design of Reliable Industrial and Commercial Power Systems (Gold Book) standard [2], about 60\% of failure-initiating causes in power transformers occur in the insulation. In addition, it has been reported that $30 \%$ of motor damage relates to insulation failure [3]. The problems associated with electrical insulation failure arise from progressive deterioration of the insulation quality under operational stresses [4]. Electrical insulation systems are therefore designed to sustain failures caused by environmental conditions, electrical as well as mechanical and chemical stresses for reliable operation over the equipment lifespan $[5,6]$.

Partial discharge (PD) activity in or on the insulation is one of the main indicators used to assess electrical insulation system quality. Hence, understanding PD phenomena allows corrective measures to be planned and implemented timely and cost effectively [7]. In the past few decades, there has been sustained progressive evolution in the researched and experienced knowledge on PD phenomena.

PD activity is influenced by many factors. These factors include humidity, temperature, altitude (air density), equipment type, and types of supply voltage. Significant research has been done on most of these factors such that there is a common understanding on how each influences PD activity. However, with regard to the supply voltage frequency, there has not been consensus on the understanding of PD characteristics' response to changes in the supply voltage frequency over a wider frequency range. 
Supply voltage frequency (SVF) versus PD mechanisms has therefore been a sustained ongoing area of PD research. The depletion of coal-based electrical energy and the emergence of grid-tied inverter-based renewable energy (solar and wind) has increased the presence of harmonics in electrical systems [8]. Harmonics and other non-power supply voltage frequencies have adverse effects on dielectric stress that still need to be fully understood [9]. Consequently, there has been sustained research on how harmonics affect PD activity [10]. On the other hand, there has been cumulative research on the influence of supply voltage frequency on partial discharges, and this is the focus of the present work.

One of the reasons why there is interest in PD behavior under different supply voltage frequencies is that there is a wide range of types of test voltages used in testing power equipment. Although most high voltage equipment operates at power frequency $(50 / 60 \mathrm{~Hz})$, the test voltage frequencies may be different. Very low frequency is preferred for testing highly capacitive equipment such as power cables. Very low frequency testing helps in reducing the power rating, cost, volume, and weight of the test equipment [11]. Inductive equipment such as power transformers are often tested at higher frequencies $(150-400 \mathrm{~Hz})[11,12]$ for reasons such as avoiding saturation in the magnetic core. Oscillating Wave Test Sets technology is also an alternative non-power frequency technique with a reduced test voltage source power rating [6,13-15]. Therefore, the question is: to what extent do PD mechanisms respond to changes in the fundamental frequency of the supply voltage?

There is no consensus among researchers, especially with regard to the effect of supply voltage frequencies on the PD mechanism. Various researchers have investigated different test voltage frequencies. Some have only investigated two frequency points such as $0.1 \mathrm{~Hz}$ and $100 \mathrm{~Hz}$ and some just $50 \mathrm{~Hz}$ and $100 \mathrm{~Hz}$. Generalized conclusions are often drawn up which can be regarded as being too brave to deduce trends from the few and too far apart data points. Due to the gaps in frequency ranges and few researchers having dealt with frequencies that are above $50 \mathrm{~Hz}$, the present paper deals with frequencies of the range from low frequencies $(1 \mathrm{~Hz})$ up to $200 \mathrm{~Hz}$.

The study approach in the present work is that of simulations. The results are validated through comparisons with measurement results obtained from the literature on similar experimental conditions. In the next section, the relevant literature is critically reviewed. The review highlights the knowledge gaps and also provides the experimentally obtained data that is then used for validating the model developed in the present work. The literature review also establishes the basis for choosing the 3-capacitor model for use in simulating PD supply voltage frequency dependency.

\section{Literature Review on the Relationship between SVF and PD Characteristics}

\subsection{The Supply Voltage Frequency (SVF)}

Various studies have been done on the influence of SVF (of different ranges) on PD mechanisms and the various parameters that influence PD characteristics. The commonly investigated PD characteristics include PD magnitude, Phase-Resolved Partial Discharge Patterns (PRPDP), PD Repetition Rate (PDRR), and PD Inception Voltage (PDIV). Significant knowledge has accumulated from research on the understanding of the relationship between SVF and PD phenomena. However, in the knowledge body, there are some inconsistencies that still need research.

It can be argued that contributing to the inconsistencies in research findings in the literature is the fact that the ranges of the supply voltages frequencies investigated vary widely. It is therefore necessary to be more comprehensive by considering a wider frequency ranging from very low frequencies through $50 \mathrm{~Hz}$ onto higher frequencies. Table 1 summarizes the landscape of the commonly used research findings in the literature. 
Table 1. Key findings in the literature on the effect of supply voltage frequency on cavity PD characteristics [16].

\begin{tabular}{|c|c|c|c|c|}
\hline Researchers & Frequency Ranges & Defect Types & Parameters & Key Findings \\
\hline Seri et al. [17] & $\mathrm{DC}$ to $60 \mathrm{~Hz}$ & $\begin{array}{l}\text { disc-shaped cavity } \\
\text { embedded in } \\
\text { polymeric insulation }\end{array}$ & $\begin{array}{l}\text { - PDRR } \\
\text { - PD amplitude }\end{array}$ & $\begin{array}{l}\text { - PDRR increases due to } \\
\text { increase in SVF. } \\
\text { - PD charge amplitude } \\
\text { increases due to increase } \\
\text { in SVF. }\end{array}$ \\
\hline Forssen \& Edin [18-20] & 0.01 to $100 \mathrm{~Hz}$ & $\begin{array}{l}1.5-10 \mathrm{~mm} \text { depth } \\
\text { disc-shaped cavities } \\
\text { in polycarbonate }\end{array}$ & $\begin{array}{l}\text { - PDRR } \\
\text { - PD magnitude } \\
\text { (max, min, mean) }\end{array}$ & $\begin{array}{l}\text { - maximum PD magnitude } \\
\text { decreases, with decrease } \\
\text { in SVF. } \\
\text { - minimum PD magnitude } \\
\text { invariant with changes } \\
\text { in SVF. } \\
\text { - PDRR decreases with } \\
\text { decrease in SVF. }\end{array}$ \\
\hline Forssen \& Edin [21] & 0.02 and $100 \mathrm{~Hz}$ & $\begin{array}{l}1.5-10 \mathrm{~mm} \text { depth } \\
\text { disc-shaped cavities } \\
\text { in polycarbonate }\end{array}$ & $\begin{array}{l}\text { - PD magnitude } \\
\text { - PRR }\end{array}$ & $\begin{array}{l}\text { - PDRR decreases with } \\
\text { increase in SVF. } \\
\text { - PRPDP changed. } \\
\text { - maximum PD magnitude } \\
\text { reduces due to increase } \\
\text { in SVF. }\end{array}$ \\
\hline Illias et al. [22] & 0.01 to $100 \mathrm{~Hz}$ & $\begin{array}{l}1 \text { mm depth } \\
\text { spherical cavity in } \\
\text { epoxy resin }\end{array}$ & $\begin{array}{l}\text { - PD charge (mean } \\
\text { and maximum) } \\
\text { - PDRR }\end{array}$ & $\begin{array}{l}\text { - PDRR decreases due to } \\
\text { increase in SVF. } \\
\text { - PD magnitude reduces } \\
\text { due to increase in SVF. }\end{array}$ \\
\hline Illias et al. [23-26] & $\begin{array}{l}0.5 \text { to } 50 \mathrm{~Hz} \\
0.1 \text { and } 50 \mathrm{~Hz}\end{array}$ & $\begin{array}{l}1-2.3 \mathrm{~mm} \text { depth } \\
\text { spherical cavity in } \\
\text { epoxy resin }\end{array}$ & $\begin{array}{l}\text { - PDRR } \\
\text { - total apparent } \\
\text { charge } \\
\text { - PD magnitude }\end{array}$ & $\begin{array}{l}\text { - PDRR increases due to } \\
\text { increase in SVF. } \\
\text { - maximum PD magnitude } \\
\text { reduces due to decrease } \\
\text { in SVF. } \\
\text { - mean charge reduces with } \\
\text { increased SVF. }\end{array}$ \\
\hline Miller \& Black $[27,28]$ & 0.1 to $50 \mathrm{~Hz}$ & $\begin{array}{l}4 \text { mm diameter } \\
\text { cylindrical cavity } \\
\text { in epoxy resin }\end{array}$ & $\begin{array}{l}\text { - PDIV } \\
\text { - PD magnitude }\end{array}$ & $\begin{array}{l}\text { - PDIV invariant with } \\
\text { changes in SVF. } \\
\text { - reduced PD magnitudes at } \\
\text { lower SVF than at } \\
\text { higher SVF. }\end{array}$ \\
\hline $\begin{array}{c}\text { Fynes-Clinton \& } \\
\text { Nyamupangedengu [29] }\end{array}$ & 0.1 and $50 \mathrm{~Hz}$ & $\begin{array}{l}1-2 \mathrm{~mm} \text { v-shaped } \\
\text { cavity in XLPE }\end{array}$ & $\begin{array}{l}\text { - PDIV } \\
\text { - apparent } \\
\text { magnitude } \\
\text { - PRPDP }\end{array}$ & $\begin{array}{l}\text { - PRPDP not affected by } \\
\text { SVF. } \\
\text { - increasing SVF causes } \\
\text { bigger apparent PD } \\
\text { magnitudes. } \\
\text { - higher PDIV due to } \\
\text { increased SVF. }\end{array}$ \\
\hline $\begin{array}{c}\text { Cavallini et al. [11,30]; } \\
\text { Hauschild et al. [31] }\end{array}$ & 0.1 to $300 \mathrm{~Hz}$ & $\begin{array}{l}2 \text { mm diameter } \\
\text { spherical cavity in } \\
\text { epoxy resin }\end{array}$ & $\begin{array}{l}\text { - PRPDP } \\
\text { - PDIV } \\
\text { - maximum } \\
\text { magnitude }\end{array}$ & $\begin{array}{l}\text { - maximum PD magnitude } \\
\text { reduces due to increase } \\
\text { in SVF. } \\
\text { - slight increase in PDIV due } \\
\text { to increase in SVF. } \\
\text { - overall shape of PRPDP } \\
\text { shifts towards zero-crossing } \\
\text { due to increase of SVF. }\end{array}$ \\
\hline Negm et al. [8] & 50 to $1000 \mathrm{~Hz}$ & $\begin{array}{l}1.5 \mathrm{~mm} \text { diameter } \\
\text { cavity }\end{array}$ & $\begin{array}{l}\text { - PDRR } \\
\text { - PRPDP } \\
\text { - PD charge }\end{array}$ & $\begin{array}{l}\text { - PDRR and PD magnitude } \\
\text { decreases due to increase } \\
\text { in SVF. } \\
\text { - PRPDP overall shape has a } \\
\text { wider spread at higher SVF. }\end{array}$ \\
\hline Haghjoo et al. [32] & 50 and $100 \mathrm{~Hz}$ & $\begin{array}{l}1 \mathrm{~mm} \text { diameter } \\
\text { cavity }\end{array}$ & $\begin{array}{l}\text { - PRPDP } \\
\text { - PDRR } \\
\text { - apparent charge }\end{array}$ & $\begin{array}{l}\text { - PDRR decreases due to } \\
\text { increase in SVF. } \\
\text { - PD magnitude increases } \\
\text { due to increased SVF. } \\
\text { - PRPDP overall shape has a } \\
\text { wider spread at higher SVF. }\end{array}$ \\
\hline
\end{tabular}


The following highlights from the literature are evident:

- $\quad$ The most cases investigated are of the supply voltage frequency range of power frequency and below,

- The most investigated PD defect is air cavity and of thickness in the order of $1 \mathrm{~mm}$,

- $\quad$ The investigated PD characteristics are PRPDP, PDRR, PDIV, and PD magnitude.

There are disagreements and inconsistencies on how PRPDP relates to the frequency of the supply voltage. Bodega et al. [13] and Morshuis et al. [15] concluded that the PRPDP is generally invariable with the change of supply voltage frequency. However, Cavallini and Montanari [11] reported that SVF increases the overall shape of the PRPDP and shifts towards the zero crossing of the voltage waveform. Forssen and Edin [20] also reported observing changes in PRPDP in response to variations in the SVF. However, they did not give further details on the correlations. On closer analysis of their article, their findings were opposite than those reported by Cavallini and Montanari [11]. Inconsistencies in the findings by various researchers on the relationship between SVF and PRPDP can be attributed to the statistical nature and deterministic memory effect in PD mechanisms.

PD repetition rate and PD amplitude are the other parameters that have been widely investigated for dependency on SVF variations. As with the PRPDP characteristic, there is generally a balance between agreement and inconsistencies with regard to findings by researchers on how PDRR and magnitude respond to changes in SVF.

Despite the agreements and shortcomings on the findings of PD activity's frequency dependency, there has been consensus on the identification of factors involved in influencing how supply voltage frequency affects PD activity. The factors are: statistical time lag, surface conductivity of the cavity, and the residual charge decay [22,33]. These factors influence PD mechanisms in complex, sometimes synergistic and in some cases in opposition. In that regard, PD models become useful in analyzing each PD characteristic's response to SVF as influenced by variations in each PD mechanism's parameter. The next section is a review of PD modeling techniques.

\subsection{PD Models Overview}

Generally, PD modeling can be classified into three categories, namely: the 3-capacitor (ABC), analytical models, and Finite Element Analysis or electric current and electrostatic model. Modeling has facilitated better understanding of PD mechanisms and complemented experimental measurement-based studies. In a recent contribution, Pan et al. [34] presented a useful state-of-the art review of PD models. In essence, each modeling technique has strengths and weaknesses depending on the context of its application.

The ABC PD model can be described as representing the PD specimen as an assemble of equivalent capacitors; the A, B, C capacitors. The PD event becomes the act of repetitive discharging and charging the capacitor that represents the cavity.

Danikas [35] critiqued the use of the classical ABC model as a tool for estimating PD magnitude. He identified the disadvantages of using the classical ABC model in that a cavity cannot be treated as pure capacitance as this can only be true if the cavity is bounded by metallic electrodes. In that regard, the Pedersen (induced-charge) model could be considered as a better option because it incorporates the geometry and positioning of the cavity in the insulation although it assumes a full volume discharge of the cavity. However, the Pedersen model has its own disadvantages such as the assumption of complete volume discharge which is open to question, and that the predictive power of the model starts deviating for larger cavities.

Achillides [36,37] critically compared and contrasted the commonly used PD models in response to criticisms of the $\mathrm{ABC}$ model. The author argued that the ABC model is capable of representing PDs based on the change of capacitance, and that the non-equipotential distribution on the surface walls is just a geometrical constraint that does not affect the main PD characteristics of interest [37]. There are possible mitigations on the equipotential and geometric constraints that include appropriate arrangement of equivalent capacitors. 
Similarly, many authors have proven in various ways that the ABC PD model is generally a valid and powerful tool for analyzing PD phenomena [32,36,37].

Despite the advantages and disadvantages of each PD modeling technique, the PD models have generally been useful in confirming the common understanding of PD mechanisms theory. PD models can be used in investigating various aspects of PD such as dependency on frequency of the supply voltage. The ABC model is a strong candidate for such a study for the following reasons: (i) it requires less computing power than the other types of PD models, (ii) the various parameters in PD mechanisms can be discretely controlled, and (iii) the model can be modified to incorporate other aspects of PD mechanisms such as cavity surface conductivity and seed electron availability. In the next section, a more detailed literature review of the ABC PD model is presented.

\subsection{The 3-Capacitor ( $A B C)$ PD Model Overview}

Achillides [37] outlined the evolution account of the ABC PD model that was pioneered by Germant and Philippoff. The $\mathrm{ABC}$ model reduces the discharging cavity and surrounding dielectric medium to a set of equivalent capacitances. A PD event is equivalent to discharging the capacitor that represents the cavity. Whitehead in 1952 [32] incorporated a statistically controlled switch across the discharging capacitor in the model to more accurately represent the statistical nature of PD.

Boggs [38] used the ABC model to describe the occurrence of PD activity in solid dielectrics. Toader and Mariana [39] improved the model to meet their requirements of investigating and obtaining the apparent charge and PD energy. Christina et al. [40] improved the extended Whitehead model to study the influence of increasing applied voltage amplitude across different void sizes. These properties help on further understanding the efficacy of the ABC model in dealing with different parameters. Danikas et al. [41] compared the simulated and experimented results from polyethylene samples using artificial cylindrical voids. The PD model used for the simulated results is the ABC model. The simulated and experimental results compared well, thereby further proving the efficacy of the classical ABC model in PD activity analysis.

Paoletti and Golubev $[3,42,43]$ presented a modified ABC model in contrast with the classical one. The insulation and cavity are each represented by a parallel combination of equivalent capacitors and resistors [44]. The cavity surface conductivity is represented by an equivalent resistor in parallel with the equivalent capacitor. The same approach is also used by Takahashi et al. [45]. They argued that the 3-capacitor model is too simple to be used in the modeling of PD phenomena. Hence, they investigated the behavior of the 3-capacitor model with dissipation since such effect cannot be ignored in real phenomena. The dissipation effect is modeled as resistance in parallel with the discharge gap. This modification is of interest in the present paper where the effect of the variations of cavity surface conductivity on PD characteristics' response to changes in SVF is investigated.

The ABC model is also used on investigating the interaction of PD in two closely coupled cavities by Agoris et al. [46]. The gas cavities and the dielectrics are modeled as lumped capacitances. The breakdown events are then modeled as voltage-controlled switches that are in parallel to the cavities. These modifications give ideas on how the $\mathrm{ABC}$ model can be modified to understand the interaction that multiple voids have on each other. Chia and Liew [47] implemented switching logic on the lumped capacitance model. The breakdown voltage in the respective multiple voids governs the switching logic of the lumped capacitance. Multiple capacitors can be strategically implemented to further identify and understand the precise nature of the PD activity within voids. The improvements are of importance to note if the present work is to be extended to cavity PD occurrence in closely coupled multiple voids.

Further work by Achillides et al. [48] improved the classical ABC model of a gascavity based on streamer concepts (such as inception and propagation) of the breakdown mechanism of gas by using a voltage-controlled triggering device in controlling an ideal switch. The switch is ON when the voltage in the cavity reaches the minimum level and 
is OFF when the voltage across the cavity is below the calculated voltage level. The ON and OFF values are calculated depending on cavity properties which include geometry and location. The present paper adapted and extended the concept of voltage controlled switching.

In addition to the work by Achillides et al. [48], Gowda and Anandraj [5] modified the original basic $A B C$ model by also implementing a circuit breaker switch that is controlled by a signal. Instead of using an ideal switch, they used a comparator switch that takes in the voltage across the cavity and compares it with the set breakdown voltage. If the voltage across the cavity exceeds the breakdown voltage, then the circuit breaker operates its ON and OFF states. In addition, a resistor is placed in parallel with the capacitor to represent the insulation resistance of the material. The concept of cavity voltage comparison with preset inception voltage, and the ON and OFF states are adapted in the present paper.

Chen et al. [49] present a capacitance equivalent circuit model for partial discharges occurring in transformer oil bubbles. The modified conditions include: (i) the manipulation of discharge time using controlled switches, (ii) representation of the role of space charge and residual voltage using controlled current switching and voltage sources, respectively, and (iii) a protective resistance, filter inductance, and detection impedance in series with each other added for better approximation of simulated results to the measured apparent PD magnitudes. The influence of residual voltage, role of space charge, and inception and extinction voltage can then be examined by adjusting the modified conditions and parameters. With residual charge effect being another frequency dependent variable of interest, these modifications could be adapted to a cavity in solid dielectric insulation to understand the role of residual charge.

Haghjoo et al. [32] successfully used the concept of the PD model but applied in the context of the air-filled cavities embedded in medium voltage power cable insulation. Variables such as the cavity air pressure and temperature and statistical time lag of the seed electrons were modeled analytically as mathematical expressions and incorporated into the model components such as those determining residual voltage in the cavity and the statistically controlled switch function. Van Jaarsveldt and Gouws [50] used the same concept and implemented in MATLAB ${ }^{\circledR}$ Simulink ${ }^{\circledR}$ to host the modified ABC PD model. The same approach is adopted in the present work but using parallel plate electrode geometry.

Negm et al. [8] analyzed both the dipole and the ABC model but ultimately employed the latter model. They developed a frequency-dependent PD model to investigate the influence of the statistical time lag and trap time constant of variable frequency of the applied voltage on charge distribution and PD magnitude. The model uses capacitors in parallel with resistors to represent permittivity and conductivity through, around, below and above a cavity. The work by Negm et al. [8] is of particular interest to the present work as it investigates frequency dependence of PD phenomena. However, their work mainly focused on the statistical time lag while, in the present work, the cavity surface conductivity will also be comparatively investigated.

Of interest is the numerical modeling review of PDs in dielectric-bounded cavities. Pan et al. [34] summarize the various ABC PD models in the literature. They present circuit structures, characteristics, and explanations for each of the capacitance models. The model is used to simulate situations of double cavities, residual space charge effects and insulation resistance, cavity and surface resistance, as well as the discharge channel resistance. The circuit structures presented give insights on the implementation and placement of components (resistors and capacitors) on the PD model used in the present paper.

Lastly, from the above background and review of PD modeling presented in the literature, the choice on the ABC PD model structure or modification best to implement depends on the requirements, specifications, and area of focus that the user wants to simulate [51]. Combining some of the aspects, modifications and circuit architectures reviewed in this section, the PD model in the present work is implemented in order to 
study the supply voltage frequency-dependent PD mechanisms. The model drawn out from different variations and combinations as reviewed above is presented in the next section to represent the statistical time lag and the cavity surface conductivity.

\section{Using the ABC PD Model to Study the Influence of Voltage Frequency on PD Characteristics}

The ABC PD model equivalent electrical circuit and values used shown in Figure 1 and Table 2 below are implemented in MATLAB ${ }^{\circledR}$ Simulink ${ }^{\circledR}$.

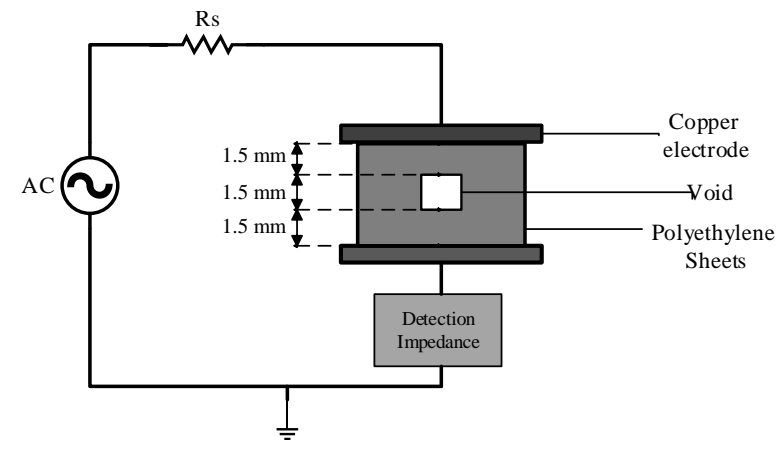

(a)

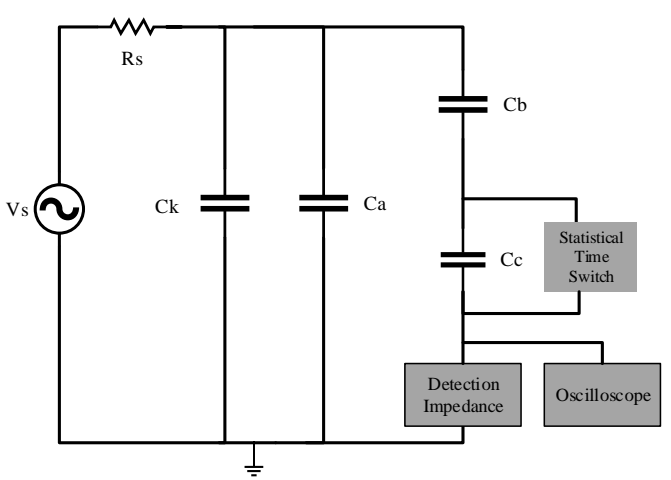

(b)

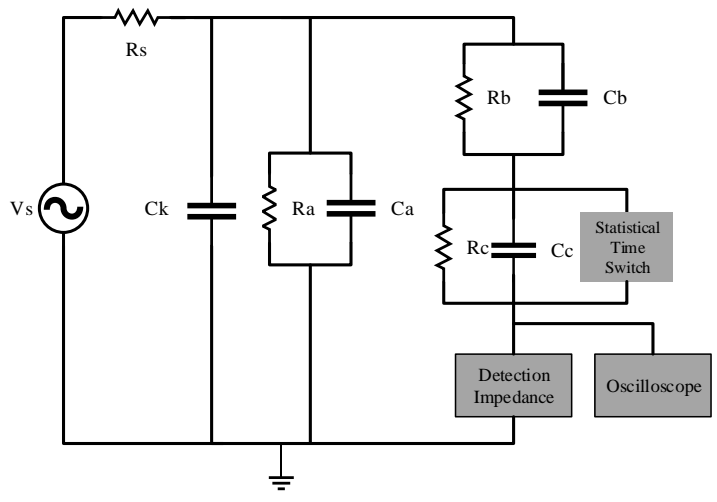

(c)

Figure 1. Equivalent circuit of the PD detection system with the ABC model implemented in MATLAB ${ }^{\circledR}$ Simulink $^{\circledR}$. (a) schematic of test specimen; (b) capacitors only model; (c) capacitors with resistors model.

Table 2. Parameter definition and values used for the ABC model simulated in MATLAB ${ }^{\circledR}$ Simulink $^{\circledR}$.

\begin{tabular}{ccc}
\hline Parameter & Definition & Value \\
\hline$R_{s}$ & Supply source current limiting resistor & $5.0 \times 10^{2} \Omega$ \\
$C_{k}$ & Coupling capacitor & $1.0 \times 10^{-9} \mathrm{~F}$ \\
$R_{a}$ & Equivalent resistance of the healthy part of the dielectric & $2.0 \times 10^{15} \Omega$ \\
$C_{a}$ & Capacitance of the healthy part of the dielectric & $1.5 \times 10^{-10} \mathrm{~F}$ \\
$R_{b}$ & Equivalent resistance of the dielectric in series below and above the cavity & $3.0 \times 10^{14} \Omega$ \\
$C_{b}$ & Capacitance of the dielectric in series below and above the cavity & $1.0 \times 10^{-12} \mathrm{~F}$ \\
$R_{c}$ & Equivalent resistance of cavity surface & $6.4 \times 10^{12} \Omega$ \\
$C_{c}$ & Capacitance of the cavity & $3.0 \times 10^{-13} \mathrm{~F}$ \\
$V_{s o}$ & Cavity spark-over voltage & $12 \mathrm{kV}$ \\
$V_{\text {ext }}$ & Cavity extinction voltage & $10 \mathrm{kV}$ \\
\hline
\end{tabular}

A partial discharge occurs when two conditions are met: (i) there is sufficient electrostatic potential energy (electric field strength) in the cavity that exceeds the cavity's breakdown strength and (ii) there is the availability of a starting 'free' electron so as to initiate a critical electron avalanche [52]. The inception electric field is dependent on the applied voltage amplitude amongst other factors. The voltage across the electrodes at 
which the cavity breakdown strength is exceeded is the PD inception voltage (PDIV). The corresponding voltage across the cavity at which the cavity breaks down is the gap spark-over voltage $\left(\mathrm{V}_{\text {so }}\right)$. The voltage at which the discharge stops is PD extinction voltage (PDEV). The incorporation into a model of the above mentioned PD parameters (PD inception voltage, gap spark-over gap, starting electron availability, PD extinction voltage) is a key necessity of any PD modeling. Figure 2 presents the flowchart of the sequence and logical steps followed when executing a PD event in MATLAB ${ }^{\circledR}$ Simulink ${ }^{\circledR}$.



Figure 2. Flow diagram of the implemented PD model [53].

\subsection{The Cavity Spark-Over Voltage}

Callender and Lewin [54] highlighted the origins and limitations of the physical concepts used in PD phenomena modeling. The discussion was restricted to cavity PD occurrence in $\mathrm{AC}$ systems that is relevant in the present work. A critique of the applicability of PD modeling to the physical phenomena is provided. Of particular interest, in the context of the present work, is the PD inception electric field. The analytical expression representing the critical field intensity that initiates self-propagating electron avalanches in a PD event is given by Equation (1) [54]:

$$
E_{c r}=A p\left[1+\frac{B}{(p L)^{\frac{1}{2}}}\right]
$$


where $E_{c r}\left(\mathrm{Vm}^{-1}\right)$ is the initiating critical electric field, $A$ and $B$ are constants $24.2 \mathrm{VPa}^{-1} \mathrm{~m}^{-1}$ and $8.6 \mathrm{~Pa}^{\frac{1}{2}} \mathrm{~m}^{\frac{1}{2}}$, respectively, $p$ is the gas pressure in a cavity $(\mathrm{Pa})$, and $L$ is the cavity length $(m)$ in the direction of the electric field.

The inception field equation was empirically determined from a system with bigger discharge gaps (in cm range) which differs from the PD system of smaller gaps (in $\mathrm{mm}$ range). The deviations that may arise on the gap spark-over voltage from extrapolation are not unexpected. Alternatively, the discharge gap spark-over voltage can be determined using the Paschen curve. The Paschen curve approach is adopted in this present work in setting up the gap spark-over voltage as it is specifically for discharge in smaller gaps. Assuming the standard conditions for temperature and pressure for a $1.5 \mathrm{~mm}$ cylindrical void, a breakdown voltage $\left(\mathrm{V}_{b}\right)$ of $\approx 8 \mathrm{kV}$ is determined. In the simulations, however, a gap spark-over voltage of $12 \mathrm{kV}$ (i.e., $\mathrm{V} s o=1.5 \mathrm{~V}_{b}$ ) is used to cater for changes or deviations of cavity conditions from standard temperature and pressure ones. After setting the gap spark-over voltage, the other condition for PD to initiate is the availability of the seed electron that is presented in the next section.

Despite some disagreements elsewhere as highlighted in Section 2.1 in the literature, the factors causing PD activity to respond to the changes in the supply voltage frequency are generally agreed to be the statistical time lag, surface resistance of the cavity, and the residual charge decay $[22,33]$. In the present paper, the cavity PD parameters investigated are the statistical time lag, as well as the surface resistance of the cavity wall. The next sections explain how the two variables were implemented in the model.

\subsection{Statistical Time Lag}

The condition of the availability of a 'free/seed/initiatory' electron is implemented in the Simulink ${ }^{\circledR}$ model in two stages. Firstly, a probability value representing seed electron availability is set. Secondly, random numbers are generated to represent the stochastic behavior occurrence into the model. The set probability value in the first stage is then used as a condition to check against the random generated numbers in setting the seed electron availability. For instance, for randomly generated numbers between 0 and 1 , setting probability values of $0.25,0.5$, and 1 , respectively, represent a $25 \%, 50 \%$, and $100 \%$ seed electron availability, respectively.

In order to investigate the effect of statistical time lag influence on supply voltage frequency dependence, all of the other parameters of the PD model are kept constant. The only adjusted parameter is the seed electron probability represented by the statistical time switch subsystem as shown in Figure 1. For a scarcity probability (25\%) of the seed electron availability, the supply voltage frequency is swept from $1 \mathrm{~Hz}$ to $200 \mathrm{~Hz}$, and the changes in the PD characteristics are noted. This simulates scarcity of the seed electron in situations of unvented and unaged cavity defects. The process is repeated for abundancy seed electron availability of $100 \%$, signifying the ready presence of the 'starting' electron. For both cases of abundancy and scarcity of seed electron availability, the frequency of the supply voltage is varied while observing the PRPDP, PD pulse amplitude, and PDRR. Simulation results are compared and contrasted with reference to the physically measured results available in the literature.

\subsection{Cavity Surface Resistance}

The surface resistance of the cavity walls is another supply voltage frequency dependent mechanism factor investigated in this paper. The resistor, $R_{c}$, in parallel with the cavity capacitor as shown in Figure 1c represents the surface resistance of the cavity walls. It is assumed that the conductivity of the air in the cavity is negligible. In order to investigate how the PD process at each frequency of the supply voltage responds to variation of the cavity surface resistance $\left(R_{c}\right)$, the statistical time lag and other PD model parameters are held constant. The cavity's surface resistance is then varied whilst observing the resultant PD characteristics at each supply frequency. The process is repeated as the supply voltage frequency is swept from $1 \mathrm{~Hz}$ to $200 \mathrm{~Hz}$. The simulated results are then compared and 
contrasted with the measured experimental results available in the literature. In addition, the simulation results of the capacitor only ABC model and the capacitors with resistors modified ABC model were compared as presented in the next section.

\section{Results and Discussion}

The outcomes of the simulations are presented in this section. The extent to which the statistical time lag, and cavity surface resistance influence SVF-dependent PD characteristics is presented.

4.1. The Extent to Which Cavity Surface Resistance Influences the PD Characteristics' Response to SVF Variations

In order to observe the effect of surface resistance on PD characteristics at different supply voltage frequencies, the cavity surface resistance, $R_{c}$, is varied from $R_{\min }$ to $R_{\max }$. Typical values of $\mathrm{R}_{\min }$ and $\mathrm{R}_{\max }$ are obtained from the literature $[8,55,56]$. It is noted that the terminology of 'conductivity' is commonly used in the cited literature. However, for the purpose of the simulation in the present work, resistance is used. The seed electron probability is set to abundancy $(100 \%)$ in all cases. The procedure is repeated for different frequencies. Results for SVF of $1 \mathrm{~Hz}, 50 \mathrm{~Hz}$, and $200 \mathrm{~Hz}$ and PD characteristics are plotted and presented as shown in Table 3.

Table 3. Cavity surface resistance influence on PD characteristics at different frequencies. $R_{c}$ values used: $R_{\min }$ is $6.0 \times 10^{9} \Omega$ and $R_{\max }$ is $6.0 \times 10^{12} \Omega$ as obtained from Hudon et al. [55] and Morshuis [56].




The general trend in Table 3 results is that the PRPDP and PDRR characteristics are more sensitive to variations in the cavity surface resistance at lower supply voltage frequencies than at higher supply voltage frequencies. A possible practical implication of this trend is that since cavity surface conductivity increases with PD defect ageing; a frequency sweep while monitoring the response of the PRPDP and PDRR can reveal whether the defect is aged or not. This behavior, however, is opposite that of the seed electron's statistical time lag.

The change of PDRR for different values of cavity surface resistance at different frequencies $(1 \mathrm{~Hz}, 50 \mathrm{~Hz}$, and $200 \mathrm{~Hz})$ is shown in Figure 3. At $1 \mathrm{~Hz}$ (lower frequency), varying the cavity surface resistance has an effect on PDRR. The sensitivity of PDRR to changes of cavity surface resistance is highest at $50 \mathrm{~Hz}$. The responsible mechanism would be a subject of future research.

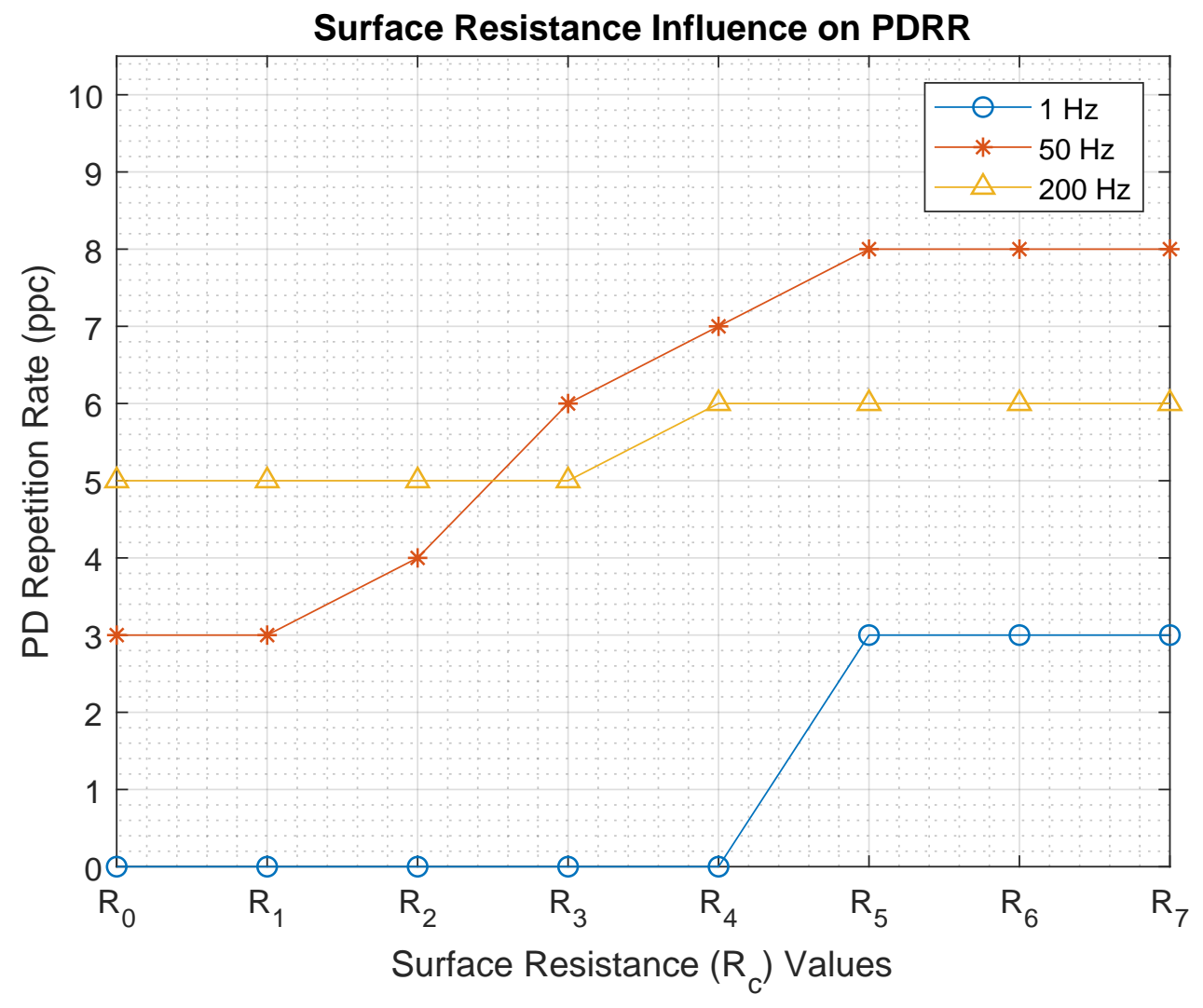

Figure 3. Cavity surface resistance influence on PDRR at different frequencies. Surface Resistance $\left(R_{c}\right)$ values: $R_{0}=3.0 \times 10^{9} \Omega, R_{1}=6.0 \times 10^{9} \Omega, R_{2}=9.0 \times 10^{9} \Omega, R_{3}=3.0 \times 10^{10} \Omega, R_{4}=9.0 \times 10^{10} \Omega$, $R_{5}=6.0 \times 10^{12} \Omega, R_{6}=9.0 \times 10^{12} \Omega$, and $R_{7}=3.0 \times 10^{15} \Omega[55,56]$.

4.2. The Extent to Which the Statistical Time Lag Influences the PD Characteristics' Response to SVF Variations

In order to observe the effect of the statistical time lag on PD characteristics as a function of supply voltage frequency, the seed electron probability is set to $25 \%$ and $100 \%$ representing scarcity and abundancy, respectively. The resultant PD phase-resolved patterns are plotted and presented for the frequencies: $1 \mathrm{~Hz}, 50 \mathrm{~Hz}$, and $200 \mathrm{~Hz}$ as shown in Table 4. The trend is that, at lower frequencies, PD characteristics do not respond to variations in the statistical time lag. At higher frequencies, however, variations in the statistical time lag change the PRPDP and PDRR. 
Table 4. Statistical time lag influence on PD characteristics at different frequencies.

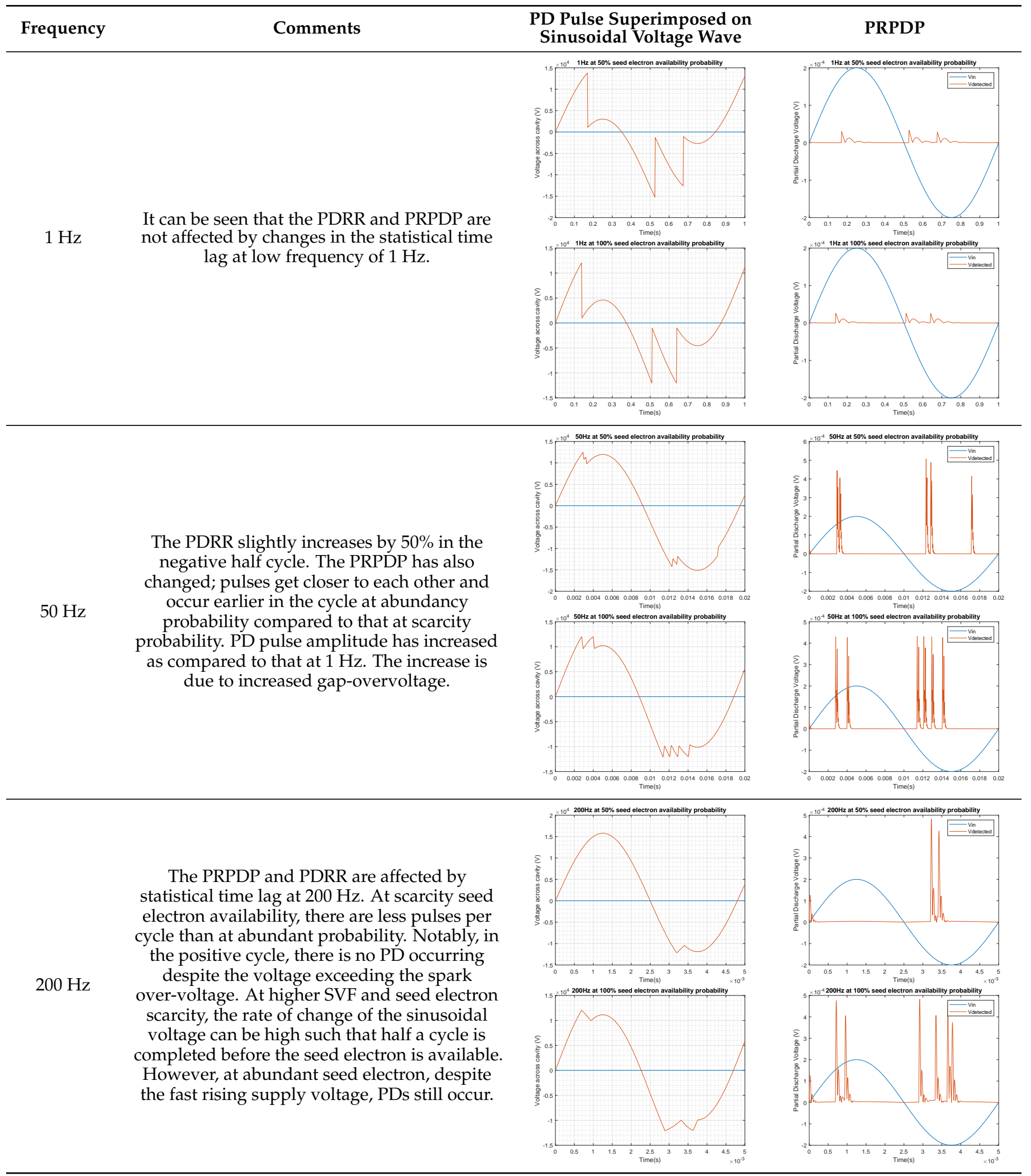




\subsection{Comparison of Capacitor Only ABC and Modified ABC Model; Simulation Results versus Experimentally Measured Results Obtained from the Literature}

This section is a comparison of the efficacy of the $A B C$ model with and without resistance components. Simulations are done for the same situations using both models. The model that gives results closer to the practically obtained in the literature is regarded as being more accurate. The pulses per cycle as a function of the supply voltage amplitude and frequency are presented in Figure 4.

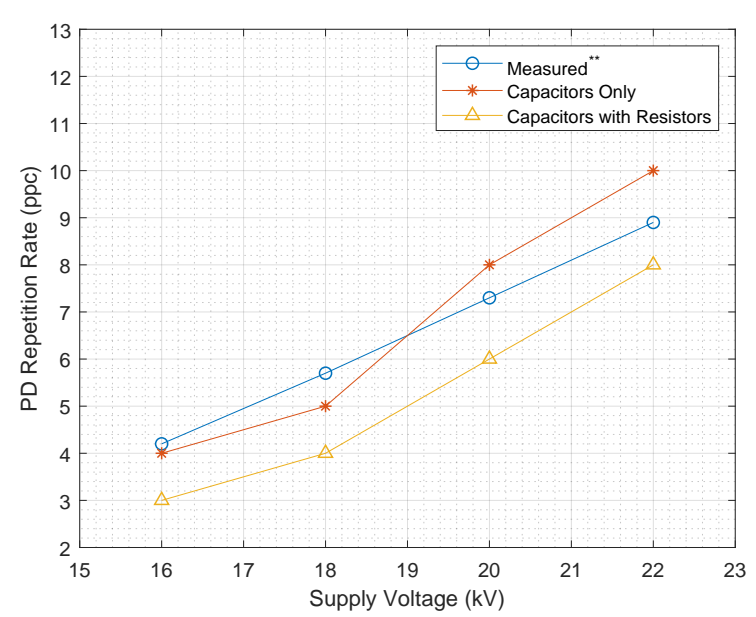

(a)



(b)

Figure 4. Simulated results using capacitors only ABC model and capacitors with resistors model plotted together with measured data obtained from the literature (a) supply voltage amplitude $\left(^{* *}\right.$ : measured values as reported by Illias et al. [26]; NB: The last point at $22 \mathrm{kV}$ has been extrapolated); (b) supply voltage frequency (***: measured values as reported by Cavallini et al. [11]).

The pulses per cycle increase as the applied voltage amplitude is increased as seen in Figure 4a. This is because increasing the applied voltage amplitude increases the electric field strength in the cavity. Increase in the electric field strength in the cavity increases the number of PD events per cycle of the sinusoidal voltage waveform.

Figure $4 \mathrm{~b}$ shows the relationship between the PDRR and the supply voltage frequency. Simulated results of both models are compared to the measurements as obtained from the literature. In addition to the experimental measurements in literature, more points are added to the simulated results to fill in the gaps of frequencies between $50 \mathrm{~Hz}$ and $300 \mathrm{~Hz}$. The trends are similar to those of the experimental measurements. PDRR increases as supply voltage frequency is increased from $1 \mathrm{~Hz}$ to $50 \mathrm{~Hz}$. This trend has been reported by a notable number of researchers who have studied the frequency range from $0.01 \mathrm{~Hz}$ up to $50 \mathrm{~Hz}[19,20,23,25,26,57]$. However, beyond $50 \mathrm{~Hz}$, the PDRR decreases with an increase in SVF. This trend has been reported by some researchers who have studied frequency ranges that are above $50 \mathrm{~Hz}$. However, researchers studying frequencies above $50 \mathrm{~Hz}$ have been relatively few. Some researchers have studied up to $100 \mathrm{~Hz}[21,22,32]$ and others have only taken two supply frequency points to draw out their conclusions. Extrapolations in Figure $4 \mathrm{~b}$ therefore help in giving a more complete picture. Negm et al. [8] studied the frequencies in the range $50 \mathrm{~Hz}$ to $600 \mathrm{~Hz}$. They noted that an increase in supply frequency decreases the number of pulses per cycle, which is in agreement with the simulation results in the present work.

The present work has investigated statistical time lag and surface conductivity with respect to how they affect the PD characteristics' dependence on variations of the SVF. The $A B C$ model used that incorporated two of the frequency dependent mechanisms (statistical time lag and cavity surface conductivity) is more realistic to the practical occurrence of the PD phenomena. It is however notable that the residual charge deposited on the cavity surfaces after every PD event can also influence the PD characteristics' response to 
variations in the supply voltage frequency [58]. Incorporation of the residual charge in the $\mathrm{ABC}$ model could therefore be an interesting future extension of the work presented in this paper.

\section{Conclusions}

In PD phenomena, it is necessary to understand how the various discharge parameters influence the manner in which PD characteristics respond to variations in the supply voltage frequency. In this paper, the PD mechanism parameters investigated are the probability of seed electron availability and cavity surface resistance. The analysis was done through simulations using the modified ABC PD model implemented in MATLAB ${ }^{\circledR}$ Simulink ${ }^{\circledR}$. The findings are that the phase-resolved PD pattern and PD repetition rate characteristics are more sensitive to variations in the availability probability of the seed electron at higher frequencies of the supply voltage. At scarce seed electron availability, the pulse repetition rate is lower than that at abundant seed electron availability. The opposite trend is observed for the cavity surface resistance in the sense that at higher frequencies of the supply voltage, the variation of the cavity surface resistance from minimum to maximum possible values result in unnoticeable changes in both phaseresolved PD patterns and the PD repetition rate. At lower SVF, variations of the cavity surface resistance from minimum to maximum result in noticeable changes in PRPDP and PDRR. These findings confirm the complexity of PD mechanisms that partly explains why there have been inconsistencies in findings by various researchers on the relationship between PD characteristics and SVF variations. The paper also concludes that incorporating resistors in parallel with the capacitors in the $\mathrm{ABC}$ model makes it more realistic than the model made up of capacitors only.

Author Contributions: The authors have contributed to different parts of the paper preparation as follows: Conceptualization, T.V. and C.N.; methodology and software, T.V.; validation and analysis, T.V. and C.N.; writing—original draft preparation, T.V.; writing—review and editing, T.V. and C.N.; supervision, C.N. All authors have read and agreed to the published version of the manuscript.

Funding: This research received no external funding.

Conflicts of Interest: The authors declare no conflict of interest.

\section{References}

1. Montanari, G.C. Envisaging links between fundamental research in electrical insulation and electrical asset management. IEEE Electr. Insul. Mag. 2008, 24, 7-21. [CrossRef]

2. Heising, C. IEEE Recommended Practice for the Design of Reliable Industrial and Commercial Power Systems (Gold Book); IEEE Std 493-1997 [IEEE Gold Book]; IEEE: Piscataway, PA, USA, 1998; pp. 1-464. [CrossRef]

3. Paolitti, G.; Golubev, A. Partial discharge theory and technologies related to traditional testing methods of large rotating apparatus. In Proceedings of the Conference Record of the 1999 IEEE Industry Applications Conference, Thirty-Forth IAS Annual Meeting (Cat. No.99CH36370), Phoenix, AZ, USA, 3-7 October 1999; Volume 2, pp. 967-981. [CrossRef]

4. McAllister, I.W. Electric field theory and the fallacy of void capacitance. IEEE Trans. Electr. Insul. 1991, 26, 458-459. [CrossRef]

5. Gowda, D. Modeling of partial discharge (PD) for solid insulation with void and building a hardware setup to measure partial discharge. In Proceedings of the 2016 Biennial International Conference on Power and Energy Systems: Towards Sustainable Energy (PESTSE), Bengaluru, India, 21-23 January 2016; pp. 1-7. [CrossRef]

6. Eigner, A.; Rethmeier, K. An overview on the current status of partial discharge measurements on AC high voltage cable accessories. IEEE Electr. Insul. Mag. 2016, 32, 48-55. [CrossRef]

7. Niemeyer, L. A generalized approach to partial discharge modeling. IEEE Trans. Dielectr. Electr. Insul. 1995, 2, 510-528. [CrossRef]

8. Negm, T.S.; Refaey, M.; Hossam-Eldin, A.A. Modeling and simulation of internal Partial Discharges in solid dielectrics under variable applied frequencies. In Proceedings of the 2016 Eighteenth International Middle East Power Systems Conference (MEPCON), Cairo, Egypt, 27-29 December 2016; pp. 639-644. [CrossRef]

9. Romano, P. Influence on PD parameters due to voltage conducted disturbances. IEEE Trans. Dielectr. Electr. Insul. 2004, 11, 160-165. [CrossRef] 
10. Florkowski, M.; Florkowska, B.; Furgał, J.; Zydron, P. Impact of high voltage harmonics on interpretation of partial discharge patterns. IEEE Trans. Dielectr. Electr. Insul. 2013, 20, 2009-2016. [CrossRef]

11. Cavallini, A.; Montanari, G.C. Effect of supply voltage frequency on testing of insulation system. IEEE Trans. Dielectr. Electr. Insul. 2006, 13, 111-121. [CrossRef]

12. IEEE PES Transformers Committee. IEEE Guide for Failure Investigation, Documentation, and Analysis for Power Transformers and Shunt Reactors; IEEE Std C57.125-1991; IEEE: Piscataway, PA, USA, 1992; pp. 1-60.

13. Bodega, R.; Cavallini, A.; Morshuis, P.H.F.; Wester, F.J. The effect of voltage frequency on partial discharge activity. In Proceedings of the Annual Report Conference on Electrical Insulation and Dielectric Phenomena, Quintana Roo, Mexico, 20-24 October 2002; pp. 685-689. [CrossRef]

14. Bodega, R.; Morshuis, P.H.F.; Lazzaroni, M.; Wester, F.J. PD recurrence in cavities at different energizing methods. IEEE Trans. Instrum. Meas. 2004, 53, 251-258. [CrossRef]

15. Morshuis, P.H.F.; Bodega, R.; Lazzaroni, M.; Wester, F.J. Partial discharge detection using oscillating voltage at different frequencies. In Proceedings of the IMTC/2002, 19th IEEE Instrumentation and Measurement Technology Conference (IEEE Cat. No.00CH37276), Anchorage, AK, USA, 21-23 May 2002; Volume 1, pp. 431-435. [CrossRef]

16. Venge, T.; Nyamupangedengu, C. Influence of Variable Frequency of the Applied Voltage on Cavity Partial Discharge Parameters: A Critical Review. In Proceedings of the 2019 Southern African Universities Power Engineering Conference/Robotics and Mechatronics/Pattern Recognition Association of South Africa (SAUPEC/RobMech/PRASA), Bloemfontein, South Africa, 29-31 January 2019; pp. 582-587. [CrossRef]

17. Seri, P.; Naderiallaf, H.; Montanari, G.C. Modelling of supply voltage frequency effect on partial discharge repetition rate and charge amplitude from AC to DC at room temperature. IEEE Trans. Dielectr. Electr. Insul. 2020, 27, 764-772. [CrossRef]

18. Forssen, C.; Edin, H. Influence of cavity size and cavity location on partial discharge frequency dependence [polymer insulation]. In Proceedings of the 17th Annual Meeting of the IEEE Lasers and Electro-Optics Society, 2004, LEOS 2004, Rio Grande, PR, USA, 11 November 2004; pp. 438-441. [CrossRef]

19. Forssen, C.; Edin, H. Partial discharges in a cavity at variable applied frequency part 1: Measurements. IEEE Trans. Dielectr. Electr. Insul. 2008, 15, 1601-1609. [CrossRef]

20. Forssen, C.; Edin, H. Partial discharges in a cavity at variable applied frequency part 2: Measurements and modeling. IEEE Trans. Dielectr. Electr. Insul. 2008, 15, 1610-1616. [CrossRef]

21. Forssen, C.; Edin, H. Modeling partial discharges in a cavity at different applied frequencies. In Proceedings of the 2007 Annual Report-Conference on Electrical Insulation and Dielectric Phenomena, Vancouver, BC, Canada, 14-17 October 2007; pp. 132-135. [CrossRef]

22. Illias, H.A.; Chen, G.; Lewin, P.L. Modeling of Partial Discharges from a Spherical Cavity within a Dielectric Material under Variable Frequency Electric Fields. In Proceedings of the 2008 Annual Report Conference on Electrical Insulation and Dielectric Phenomena, Quebec, QC, Canada, 26-29 October 2008; IEEE: Piscataway, PA, USA, 2008; pp. 447-450. [CrossRef]

23. Illias, H.A.; Chen, G.; Lewin, P.L. Partial discharge modelling in a spherical cavity within a dielectric insulation material as a function of frequency. In Proceedings of the 2009 IEEE Electrical Insulation Conference, Montreal, QC, Canada, 31 May-3 June 2009; pp. 55-59. [CrossRef]

24. Illias, H.A.; Chen, G.; Lewin, P.L. Partial discharge measurements for spherical cavities within solid dielectric materials under different stress and cavity conditions. In Proceedings of the 2009 IEEE Conference on Electrical Insulation and Dielectric Phenomena, Virginia Beach, VA, USA, 18-21 October 2009; pp. 388-391. [CrossRef]

25. Illias, H.A.; Chen, G.; Lewin, P.L. Comparison of partial discharge measurement and simulation results for spherical cavities within solid dielectric materials as a function of frequency using Finite Element Analysis method. In Proceedings of the 2010 IEEE International Symposium on Electrical Insulation, San Diego, CA, USA, 6-9 June 2010; pp. 1-5. [CrossRef]

26. Illias, H.; Chen, G.; Lewin, P.L. Partial discharge behavior within a spherical cavity in a solid dielectric material as a function of frequency and amplitude of the applied voltage. IEEE Trans. Dielectr. Electr. Insul. 2011, 18, 432-443. [CrossRef]

27. Miller, R.; Black, I.A. Partial Discharge Measurements over the Frequency Range $0.1 \mathrm{~Hz}$ to $50 \mathrm{~Hz}$. IEEE Trans. Electr. Insul. 1977, EI-12, 224-233. [CrossRef]

28. Miller, R.; Black, I.A. Partial Discharge Energy Measurements on Electrical Machine Insulation When Energized at Frequencies between $0.1 \mathrm{~Hz}$ and Power Frequency. IEEE Trans. Electr. Insul. 1979, EI-14, 127-135. [CrossRef]

29. Fynes-Clinton, D.; Nyamupangedengu, C. Partial discharge characterization of cross-linked polyethylene medium voltage power cable termination defects at very low frequency $(0.1 \mathrm{~Hz})$ and power frequency test voltages. IEEE Electr. Insul. Mag. 2016, 32, 15-23. [CrossRef]

30. Cavallini, A.; Ciani, R.; Conti, M.; Morshuis, P.F.H.; Montanari, G.C. Modeling memory phenomena for partial discharge processes in insulation cavities. In Proceedings of the 2003 Annual Report Conference on Electrical Insulation and Dielectric Phenomena, Albuquerque, NM, USA, 19-22 October 2003; pp. 723-727. [CrossRef]

31. Hauschild, W.; Cavallini, A.; Montanari, G.C. Effect of supply voltage frequency on testing of insulation system. IEEE Trans. Dielectr. Electr. Insul. 2006, 13, 1189-1191. [CrossRef] 
32. Haghjoo, F.; Khanahmadloo, E.; Shahrtash, S.M. Comprehensive 3-capacitors model for partial discharge in power cables. Compel. Int. J. Comput. Math. Electr. Electron. Eng. 2012, 31, 346-368. [CrossRef]

33. Edin, H. Partial Discharges Studied with Variable Frequency of the Applied Voltage. Ph.D. Thesis, Kungl Tekniska Hogskolan (KTH), Stockholm, Sweden, 2001.

34. Pan, C.; Chen, G.; Tang, J.; Wu, K. Numerical modeling of partial discharges in a solid dielectric-bounded cavity: A review. IEEE Trans. Dielectr. Electr. Insul. 2019, 26, 981-1000. [CrossRef]

35. Danikas, M.G. The definitions used for partial discharge phenomena. IEEE Trans. Electr. Insul. 1993, 28, 1075-1081. [CrossRef]

36. Achillides, Z.; Danikas, M.G.; Kyriakides, E. Partial discharge modeling and induced charge concept: Comments and criticism of pedersen's model and associated measured transients. IEEE Trans. Dielectr. Electr. Insul. 2017, 24, 1118-1122. [CrossRef]

37. Achillides, Z.; Georghiou, G.E.; Kyriakides, E. Partial discharges and associated transients: The induced charge concept versus capacitive modeling. IEEE Trans. Dielectr. Electr. Insul. 2008, 15, 1507-1516. [CrossRef]

38. Boggs, S.A. Partial discharge. III. Cavity-induced PD in solid dielectrics. IEEE Electr. Insul. Mag. 1990, 6, 11-16. [CrossRef]

39. Toader, M.; Mariana, D. Electrical insulation study using partial discharge model. In Proceedings of the 2000 10th Mediterranean Electrotechnical Conference, Information Technology and Electrotechnology for the Mediterranean Countries, MeleCon 2000 (Cat. No.00CH37099), Lemesos, Cyprus, 29-31 May 2000; Volume 3, pp. 1060-1063. [CrossRef]

40. Christina, A.J.; Salam, M.A.; Rahman, Q.M.; Arifin, M.S.; Wen, F.; Ang, S.P.; Hasan, S. Partial discharge modeling with increasing applied voltages across different void sizes. In Proceedings of the 2017 4th International Conference on Advances in Electrical Engineering (ICAEE), Hong Kong, China, 27-29 October 2017; pp. 22-25. [CrossRef]

41. Kolev, N.P.; Danikas, M.G.; Gadjeva, E.D.; Gourov, N.R. Development of partial discharge model, simulation and measurement. In Proceedings of the 1999 Annual Report Conference on Electrical Insulation and Dielectric Phenomena (Cat. No.99CH36319), Austin, TX, USA, 17-20 October 1999; Volume 1, pp. 214-217. [CrossRef]

42. Paoletti, G.; Golubev, A. Partial discharge theory and applications to electrical systems. In Proceedings of the Conference Record of 1999 Annual Pulp and Paper Industry Technical Conference (Cat. No.99CH36338), Seattle, WA, USA, 21-25 June 1999; pp. 124-138. [CrossRef]

43. Paoletti, G.J.; Golubev, A. Partial discharge theory and technologies related to medium-voltage electrical equipment. IEEE Trans. Ind. Appl. 2001, 37, 90-103. [CrossRef]

44. Yue, K.; Chen, J.; Ruan, H.; Qian, C. Study on partial discharge model of solid insulator. In Proceedings of the 2016 IEEE International Conference on High Voltage Engineering and Application (ICHVE), Chengdu, China, 9-22 September 2016; pp. 1-4. [CrossRef]

45. Suzuki, H.; Aihara, K.; Takahashi, T.; Okamoto, T. Deterministic Partial Discharge Model with Dissipation. In Proceedings of the IEICE International Symposium on Nonlinear Theory and its Applications (NOLTA2004), Fukuoka, Japan, 29 November-3 December 2004; pp. 143-146. [CrossRef]

46. Agoris, D.P.; Hatziargyriou, N.D. Approach to partial discharge development in closely coupled cavities embedded in solid dielectrics by the lumped capacitance model. IEE Proc.—Sci. Meas. Technol. 1993, 140, 131-134. [CrossRef]

47. Chia, P.Y.; Liew, A.C. Novel approach to partial discharge signals modeling in dielectric insulation void using extension of lumped capacitance model. In Proceedings of the PowerCon 2000, 2000 International Conference on Power System Technology, Proceedings (Cat. No.00EX409), Perth, Australia, 4-7 December 2000; Volume 3, pp. 1207-1212. [CrossRef]

48. Achillides, Z.; Kyriakides, E.; Georghiou, G.E. Partial discharge modeling: An improved capacitive model and associated transients along medium voltage distribution cables. IEEE Trans. Dielectr. Electr. Insul. 2013, 20, 770-781. [CrossRef]

49. Chen, X.; Bi, M.; Jiang, T.; Wang, Y. An equivalent circuit model for partial discharge occuring in transformer oil bubbles. In Proceedings of the 2016 IEEE International Conference on High Voltage Engineering and Application (ICHVE), Chengdu, China, 9-22 September 2016; pp. 1-4. [CrossRef]

50. Van Jaarsveldt, H.; Gouws, R. Partial discharge simulations used for the design of a non-intrusive cable condition monitoring technique. J. Energy Power Eng. 2013, 7, 2193-2201.

51. Illias, H.A.; Chen, G.; Lewin, P.L. Comparison between three-capacitance, analytical-based and finite element analysis partial discharge models in condition monitoring. IEEE Trans. Dielectr. Electr. Insul. 2017, 24, 99-109. [CrossRef]

52. Stone, G.C. Partial discharge diagnostics and electrical equipment insulation condition assessment. IEEE Trans. Dielectr. Electr. Insul. 2005, 12, 891-904. [CrossRef]

53. Venge, T.; Nyamupangedengu, C. Influence of Supply Voltage Frequency on Cavity Partial Discharge Parameters: Simulation Results. In Proceedings of the 2020 International SAUPEC/RobMech/PRASA Conference, Cape Town, South Africa, 29-31 January 2020; pp. 1-6. [CrossRef]

54. Callender, G.; Lewin, P.L. Modeling partial discharge phenomena. IEEE Electr. Insul. Mag. 2020, 36, 29-36. [CrossRef]

55. Hudon, C.; Bartnikas, R.; Wertheimer, M.R. Spark-to-glow discharge transition due to increased surface conductivity on epoxy resin specimens. IEEE Trans. Electr. Insul. 1993, 28, 1-8. [CrossRef]

56. Morshuis, P.H.F. Degradation of solid dielectrics due to internal partial discharge: some thoughts on progress made and where to go now. IEEE Trans. Dielectr. Electr. Insul. 2005, 12, 905-913. [CrossRef] 
57. Nguyen, H.V.P.; Phung, B.T.; Morsalin, S. Modelling partial discharges in an insulation material at very low frequency. In Proceedings of the 2017 International Conference on High Voltage Engineering and Power Systems (ICHVEPS), Bali, Indonesia, 2-5 October 2017; pp. 451-454. [CrossRef]

58. Patsch, R.; Berton, F. The role of space charges in PD-processes. In Proceedings of the Proceedings of 2001 International Symposium on Electrical Insulating Materials (ISEIM 2001), 2001 Asian Conference on Electrical Insulating Diagnosis (ACEID 2001), 33rd Symposium on Electrical and Ele, Himeji, Japan, 22 November 2001; pp. 21-24. [CrossRef] 